\title{
Analysis of cells obtained by bronchial lavage of infants with respiratory syncytial virus infection
}

Queen's Medical

Centre, Nottingham

Department of Child

Health

M L Everard

A Swarbrick

J McIntyre

A D Milner

Department of

Cytology

C Dunkley

P D James

Department of Immunology M Wrightham H F Sewell

Correspondence to: Dr M L Everard, University Department of Paediatrics, Princess Margaret Hospital, GPO Box D184, Perth, Western Australia 6001 Australia.

Accepted 21 July 1994

Mark L Everard, Andrea Swarbrick, Mark Wrightham, John McIntyre, Christine Dunkley, Peter D James, H F Sewell, Anthony D Milner

Abstract

To study the cellular infiltrate that occurs within the airways of infants with respiratory syncytial virus bronchiolitis, samples of airways secretions were obtained by bronchial lavage from the lower respiratory tract of infants ventilated for this condition and from the upper airway of non-intubated infants with this disorder using nasopharyngeal aspirates.

Cytospin samples were prepared so that differential cell counts could be performed on the cells obtained and alkaline phosphatase-antialkaline phosphatase immunocytochemical analysis of lymphocyte subsets was carried out using a panel of monoclonal antibodies, which included anti-CD3, anti-CD4, anti-CD8, antiCD19, and anti-TcR $\gamma \delta$.

Results from the lower and upper airways were similar. Large numbers of inflammatory cells were obtained, of which neutrophils accounted for a median of $93 \%$ in the upper airway and $76 \%$ in the lower airway. The numbers of $\mathrm{CD} 8$ positive cells detected were small and consistently less than CD4 positive cells, median CD4:CD8 ratios being 22.5:1 and 15:1 for the lower and upper airways. CD19 positive cells were rarely observed and no $\gamma \delta$ positive lymphocytes were detected.

These results indicate that neutrophils probably play a major part in causing symptoms in these infants. They do not support the concept that excessive lymphocyte mediated cytotoxic activity is principally responsible for the pathology in respiratory syncytial virus bronchiolitis. (Arch Dis Child 1994; 71: 428-432)

The respiratory syncytial virus is unique in its ability to cause yearly epidemics of respiratory disease. ${ }^{12}$ As a result almost all infants will have been infected by the virus by the second year of life and, of these, $0.5-2 \%$ develop acute bronchiolitis severe enough to be admitted to hospital. Results from studies using a formalin inactivated virus ${ }^{3}$ and other more recent attempts to produce a vaccine suggest that it is unlikely that we will be able to effectively prevent this distressing illness until the immunological mechanisms involved in the disease process, including those aspects conferring protection, are clarified.

Although there have been many studies during the past 25 years attempting to clarify the inflammatory process, most have concen- trated on the possible role of antibodies in the genesis of acute bronchiolitis and, until recently, there has been relatively little interest in the role of inflammatory cells. There has been considerable interest in the possible role of cytotoxic $\mathrm{T}$ cells as a major contributor to lung pathology. It is known that cytotoxic $T$ cells contribute to recovery from respiratory syncytial virus infection in that immunodeficient infants are prone to severe, prolonged infection with the virus. ${ }^{45}$ Animal studies using rodents have suggested, however, that these cells may also contribute to the lung disease in infants with bronchiolitis ${ }^{6}$ and analysis of samples obtained from infants vaccinated with a formalin inactivated preparation has produced data which may support this. ${ }^{7}$

Most studies investigating the role of inflammatory cells involved in the response to human respiratory syncytial virus infections have been carried out in animal models. Unfortunately, results obtained from these experiments are difficult to interpret as these animals are not the natural host for the virus and indeed rarely develop respiratory symptoms when infected. To study the cellular response to the virus in its natural host, we examined the inflammatory cell populations in the upper and lower respiratory tract of infants with acute bronchiolitis during two winter epidemics.

\section{Patients and methods}

PATIENTS

Bronchial lavage specimens were obtained from a total of 14 infants from five centres during two winter epidemics. All were intubated for respiratory syncytial virus positive bronchiolitis confirmed by indirect immunofluorescence on nasopharyngeal aspirates. The infants' ages ranged from 5 to 34 weeks. Four infants were still less than 42 weeks' gestational age when admitted. Seven infants had been born before 37 weeks' gestation, two before 34 weeks.

Nasopharyngeal secretions were obtained from a total of 20 non-ventilated infants with respiratory syncytial virus proved bronchiolitis during one winter. Their ages ranged from 2 to 38 weeks, with one infant having been born prematurely.

None of the infants in either group had been ventilated in the neonatal period and none had pre-existing cardiac or respiratory disease. Ethics committee approval was obtained for this study. 
COLLECTION OF SPECIMENS

Bronchial lavage was performed at the time of routine endotracheal suction using a technique based on one previously described for obtaining bronchial lavage samples from preterm infants with chronic lung disease. ${ }^{8}$ Infants were oxygenated for two minutes before the procedure. A suction catheter was passed through the endotracheal tube with the infant's head turned to the left. This was designed to introduce the suction catheter into the right main bronchus. Normal saline $(1 \mathrm{ml} / \mathrm{kg}$ ) warmed to $37^{\circ} \mathrm{C}$ was introduced via the catheter into the right main bronchus and after a five second delay was aspirated using $8 \mathrm{kPa}$ of suction. The aspirate was collected in a trap which was placed on ice until processing.

Nasopharyngeal samples were obtained using a standard technique in which a suction catheter was introduced into the nasopharynx via the nose. Suction was applied as the catheter was withdrawn and the secretions were collected into a mucus trap and placed on ice.

PROCESSING OF SAMPLES

The tracheal aspirates and nasopharyngeal aspirates were agitated with a pipette to break up clumps of mucus and any remaining large aggregates of mucus were then removed with a pipette. The lavage fluid was allowed to stand, so that the residual debris settled to the base of the tube. The sample fluid was then transferred to a second tube and centrifuged at $300 \mathrm{~g}$ for five minutes. The resulting supernatant was removed and frozen for subsequent analysis while the pellet of cells was resuspended in normal saline.

\section{DIFFERENTIAL CELL COUNT ON NASOPHARYNGEAL AND BRONCHIAL LAVAGE SAMPLES}

Cytocentrifugation preparations were prepared by spinning small samples at $400 \mathrm{~g}$ for five minutes at room temperature. The cell preparations were allowed to air dry and were then stained with a May-Grunwald-Giemsa stain. Differential counts were performed by counting a minimum of 500 cells using a standard microscope.

A total of 22 bronchial lavage samples from nine patients, obtained one to eight days after intubation, were prepared during the first winter. Six of these samples were obtained on day 1. Twenty two nasopharyngeal samples were prepared from a total of 20 patients obtained one to seven days after admission.

\section{ALKALINE PHOSPHATASE-ANTIALKALINE PHOSPHATASE IMMUNOCYTOCHEMICAL} ANALYSIS OF LYMPHOCYTE SUBSETS Initial attempts to use flow cytometry (FACS) to determine lymphocyte subsets were unsuccessful as the large number of activated neutrophils appeared to have a wide scatter in terms of size and fluorescence and prevented us from identifying a discrete group of lymphocytes. An alkaline phosphatase-antialkaline phosphatase (APPAP) technique was therefore used on slide preparations.

During the second winter a total of 22 slides from five patients were prepared from bronchial lavage samples and 10 slides from these five patients were prepared from nasopharyngeal aspirates. A $10 \mu \mathrm{l}$ volume of cell suspension with approximately $4 \times 10^{6}$ cells $/ \mathrm{ml}$ was added to each well of a multiwell slide (C A Hendley, London). These were air dried on the bench and stored wrapped in foil at $-20^{\circ} \mathrm{C}$. As exactly $10 \mu \mathrm{l}$ was added to each well, the number of cells within each well on a given slide should be constant as each slide contained cells from a single sample.

Slides were fixed by placing in acetone for 10 minutes followed by air drying. A $50 \mu \mathrm{l}$ volume of the appropriate monoclonal antibodies diluted one in 10 with TRIS buffered saline was placed on each spot and then incubated in a moist box for one hour and then washed in TRIS buffered saline. A $50 \mu l$ volume of rabbit antimouse immunoglobulin (DakoPatts, Ely) diluted one in 20 with TRIS buffered saline, was then applied, incubated for 30 minutes, and washed. The procedure was then repeated using $50 \mu \mathrm{l}$ of mouse APAAP (DakoPatts) diluted one in 20 with TRIS buffered saline. After washing, the slides were developed using fast red pH $9 \cdot 2$ (Sigma, Poole) as an alkaline phosphatase substrate. After washing the nuclei were counterstained with Meyer's haematoxylin, briefly placed in Scott's tap water substitute, washed, and the slides were mounted.

The monoclonal antibodies used were antiCD3 (pan T cell), anti-CD4 (T helper inducer subset and some monocytes), anti-CD8 ( $T$ cytotoxic suppressor subset), anti-CD19 (pan B cells), and anti-TcR $\gamma \delta$ (receptors of a minor $T$ cell subpopulation), together with isotype controlled immunoglobulins. The ratio of CD4 positive:CD8 positive cells for each slide was assessed using a light microscope with $\times 100$ magnification. The slide was positioned with the centre of the well in the centre of the field and all positively staining cells within that field included.

\section{Results}

The infants appeared to tolerate the lavage process well. The volume of fluid recovered was $36-54 \%$ of the fluid introduced. Total cell counts obtained from bronchial lavage samples ranged from 0.4 to $12 \times 10^{6} / \mathrm{ml}$. Sometimes the sample appeared to accumulate within the suction catheter due to mucus adhering to the catheter wall. For these samples the catheter was flushed with saline to enhance the recovery of cells.

\section{CELL DIFFERENTIALS}

In all bronchial lavage samples examined, the predominant cell type was neutrophils, accounting for a median of $76 \%$ of all cells (interquartile range $71-85 \%$ ). The corresponding values for lymphocytes and mononuclear phagocytic cells 
were $9 \%(6-16 \%)$ and $10 \%(8-12 \%)$ respectively, whereas eosinophils accounted for less than $1 \%$ of all cells seen and were identified within the 500 cells counted in only eight slides. There was no apparent relation between time from intubation and either total cell counts or the proportion of cells represented by neutrophils.

For nasopharyngeal aspirates, neutrophils were again the predominant cell type, accounting for a median of $93 \%$ (interquartile range 90.5-94\%). Corresponding values for lymphocytes and mononuclear cells were $5 \%$ $(3 \cdot 3-6 \cdot 8 \%)$ and $2 \%(2-2 \cdot 8 \%)$ respectively. No eosinophil was noted in any sample.

\section{LYMPHOCYTE SUBSETS}

$\mathrm{CD} 3$ positive, $\mathrm{CD} 4$ positive, and $\mathrm{CD} 8$ positive lymphocytes were present on all slides. CD19 positive cells were rarely identified and no $T c R \gamma \delta$ positive cells were identified on any slide. CD8 positive cells were far less numerous than CD4 positive in all slides from both the upper and lower respiratory tract. The median ratio of $\mathrm{CD} 4$ positive:CD8 positive cells in lavage sample was $22 \cdot 5: 1$ (interquartile range $8 \cdot 6-26 \cdot 5: 1$ ) and for nasopharyngeal samples it was 15:1 (8·4-18:9:1).

\section{Discussion}

The most striking observation in this study was the large number of neutrophils present in secretions from the upper and lower airways and it would therefore seem likely that these granulocytes contribute significantly to the inflammation within the airways of these infants. There have been few previous reports attempting to describe the pattern of inflammatory cells in the airways of infants with acute bronchiolitis. One group described a lymphocytic, peribronchiolar infiltrate as being characteristic of histological bronchiolitis in a small number of fixed necropsy specimens obtained from infants who had died from respiratory viral infections. ${ }^{9}$ Others have reported, in abstract form, that neutrophils are the most common inflammatory cell within the upper and lower respiratory tract of infants with bronchiolitis, accounting for around 70\% of cells recovered, ${ }^{10}$ figures similar to ours. It is well recognised in other inflammatory disorders of the lungs that neutrophils may be recovered in large numbers in lavage samples, but be present in only small numbers in biopsy specimens. ${ }^{11}$ This is believed to be due to the rapid migration of these granulocytes into the lumen and such a mechanism might explain the discrepancies between our findings and earlier histological studies.

Neutrophils generate a large number of inflammatory products, including oxidants and proteolytic enzymes, ${ }^{12} 13$ and have been implicated in the genesis of acute and chronic lung disease. ${ }^{1213}$ There is increasing evidence that in respiratory viral infections, neutrophils may have a role in host defence ${ }^{14}$ and in the causation of respiratory symptoms. In adult subjects experimentally infected with rhino- virus it is only those in whom there is an influx of neutrophils who exhibit symptoms. ${ }^{15}$ The steps leading to the influx of neutrophils observed in infants with bronchiolitis is unclear. It is known that infected cells can induce complement activation, ${ }^{1617}$ and immune complexes have been detected in nasal secretions from infected infants. ${ }^{18} \mathrm{C} 5 \mathrm{a}$, a product of complement activation, plays an important part in neutrophil chemotaxis by rapidly enhancing neutrophil adhesion to endothelial cells and also stimulates degranulation, ${ }^{13}$ whereas respiratory syncytial virus immune complexes have been shown to stimulate neutrophil activity. ${ }^{19}$ Hence antibody mediated pathology mediated through complement and neutrophils may play a central part in the disease, a concept not far removed from the original hypothesis implicating immunopathological factors in the causation of acute bronchiolitis. ${ }^{20}$ Perhaps more significant is the observation that the respiratory syncytial virus infection stimulates human alveolar macrophages $^{21}$ and airway epithelial cells ${ }^{22}$ to produce interleukin-8 in large amounts. Interleukin- 8 is known to be a potent chemotactant and activator for neutrophils ${ }^{23}$ and it is likely that this cytokine plays a central part in the neutrophil influx seen in respiratory syncytial virus infections and hence may prove to be a major contributor to the pathology and symptoms seen in acute respiratory syncytial virus bronchiolitis.

Interestingly, it has been reported that chemotaxis and adherence of neutrophils in the first month of life is impaired in term and preterm infants. ${ }^{24} 25$ This may account for the relative protection that infants appear to have from acute bronchiolitis in the first month of life when clinically overt infections are uncommon and tend to be mild in those with symptoms. ${ }^{26}$

An in vitro study indicated that the virus can activate human eosinophils, ${ }^{27}$ and a second study found that levels of eosinophil cationic protein in nasopharyngeal secretions from infants with respiratory syncytial virus bronchiolitis were higher than in samples from infants with upper respiratory tract symptoms only. ${ }^{28}$ The authors of these studies speculated that these granulocytes may play a part in the pathogenesis of the acute illness and contribute to persistent airway hyperreactivity. In our study eosinophils were not detected, or present in only low numbers, in samples from the upper and lower respiratory tract. Though eosinophil products are potent stimulators of inflammation within the respiratory tract, the low numbers within the inflammatory cells present in the respiratory tract suggest that they play only a small part in the inflammatory process.

Although the results obtained with bronchial lavage do not necessarily reflect events within the lung parenchyma, our study does not support the suggestion that classical CD3 positive/CD8 positive cytotoxic $T$ cells are central to the immunopathology of this disorder in which infection is apparently confined to the airways and epithelial surface. It remains 
possible that significant numbers of these cells remain within the parenchyma and contribute to the inflammatory process. One study has attempted to detect circulating cytotoxic $\mathrm{T}$ cells directed against respiratory syncytial virus in infants with acute bronchiolitis. ${ }^{29}$ Such cells were detected in only four of 22 infants and these were those infants with the mildest disease.

In this study it was apparent that a significant percentage of $C D$ positive cells appears not to express the CD4 or CD8 subset markers. Such double negative $\mathrm{T}$ cells commonly represent a small $(<5 \%)$ number of $\mathrm{T}$ cells in adult peripheral lymphoid tissues. This population has been shown to be capable of non-major histocompatibility complex restricted cell cytotoxicity, a property which may be important in the context of the present study. Whether this function is operative in vivo in the lungs of infants with respiratory syncytial virus bronchiolitis will require functional assays of such isolated or, indeed, cloned cell populations.

It has been proposed that $\gamma \delta$ positive T cells play an important part in interacting with infectious agents at mucosal surfaces. We were unable to detect any such cells in either the upper or lower respiratory tract of the natural host of respiratory syncytial virus. A study analysing cells obtained by bronchoalveolar lavage from experimentally infected mice found few cells staining for $T c R \gamma \delta .{ }^{30}$ It was also noted in that study that many of the lymphocytes recovered from the lungs of mice did not express $T$ cell markers. The significance of these findings in mice and humans is unclear.

The main limitation of this study, as with many studies of patients with bronchiolitis, is the absence of suitable controls. Unfortunately, suitable intubated controls were not available and hence the influence of ventilation on the pattern of inflammatory cells observed remains uncertain. Cell differentials and lymphocyte subsets obtained from the upper respiratory tract show similar trends to those obtained from bronchial lavage samples, however, and hence the process of ventilation does not appear to be the major determining factor in the observed results. Another potential problem is that processing of any lavage sample results in a loss of cells and potential selective loss of certain cell types. ${ }^{31}$ The high proportion of neutrophils obtained in the lavage samples is different to that observed in older children and healthy adults, ${ }^{32}$ however, in whom macrophages are the predominant cell recovered, ${ }^{33}$ whereas the large excess of CD4 positive cells over CD8 positive cells suggests that these changes are likely to reflect relative numbers within the airway, even if the absolute values may be influenced by processing of the samples.

This study does not answer the question of whether the immunological process occurring during respiratory syncytial virus infection is different from that occurring in those with upper respiratory tract symptoms only, but in those with upper and lower respiratory tract symptoms the inflammatory process appears to be similar. As the upper respiratory symptoms in those with and without lower respiratory tract disease are similar, it is possible that infants admitted to hospital with acute bronchiolitis do not have a specific underlying immunological predisposition to this disease, but represent one end of the spectrum of disease severity in which the spread of infection to the lower airways, together with factors such as the age of the infant ${ }^{34} 35$ and relative airways size $^{36}$ determine the pattern of illness observed. The large numbers admitted to hospital may simply reflect the fact that most infants are infected during their first year of life.

Further studies will be required to determine whether the neutrophil influx observed in infants with bronchiolitis contributes to the elimination of the virus or simply assists the dissemination of the virus through the stimulation of mucus production, coughing, and sneezing.

Dr Everard was generously supported by Asthma Nationwide.

1 Everard ML, Milner AD. The respiratory syncytial virus and its role in acute bronchiolitis. Eur $\mathcal{F}$ Pediatr 1992; 151: $638-51$

$2 \mathrm{Kim} \mathrm{KW,} \mathrm{Arrobio} \mathrm{JO,} \mathrm{Brandt} \mathrm{CD,} \mathrm{et} \mathrm{al.} \mathrm{Epidemiology} \mathrm{of}$ respiratory syncytial virus infection in Washington, DC. I Importance of the virus in different respiratory tract disease syndromes and temporal distribution of infection. Am F Epidemiol 1973; 98: 216-25.

$3 \mathrm{Kim} \mathrm{HW}$, Canchola JG, Brandt CD, et al. Respiratory syncytial virus disease in infants despite prior administration of antigenic inactivated vaccine. Am $\mathcal{J}$ Epidemiol tion of antigenic

4 Fishaut M, Tubergen D, McIntosh K. Cellular response to respiratory viruses with particular reference to children with disorders of cell-mediated immunity. $\mathcal{F}$ Pediatr 1980 96: 179-86.

5 Milner ME, Monte SM de le, Hutchins GM. Fatal respiratory syncytial virus infection in severe combined immunodeficiency syndrome. Am $\mathcal{F}$ Dis Child 1985; 139: $1111-4$

6 Cannon MJ, Openshaw PJ, Askonas BA. Cytotoxic T cells clear virus but augment living pathology in mice infected with respiratory syncytial virus. $f$ Exp Med 1988; 168: with respira.

7 Kim HW, Leikin SL, Arrobio J, Brandt CD, Chanock RM, Parrott RH. Cell-mediated immunity to respiratory syncytial virus induced by inactivated vaccine or by infecsyncytial virus induced by inactivate
tion. Pediatr Res 1976; 10: 75-8.

8 Grigg JM, Arnon S, Silverman M. Fractional processing of sequential bronchoalveolar lavage fluid from intubated babies. Eur Respir f 1992; 5: 727-32.

9 Aherne W, Bird T, Court SDM, Gardner PS, McQuillin J. Pathological changes in virus infections of the lower respiratory tract in children. F Clin Pathol 1970; 23: 7-18.

10 Faden HS, Kaul TN, Lin TY, Ogra PL. Activation and mucosal migration of polymorphonuclear leukocytes during respiratory syncytial virus infection. Pediatr Res 1984; 18: $274 \mathrm{~A}$.

11 Wilson R. Infections of the airways. Curr Opin Infect Dis 1991; 4: 166-75.

12 Sibille Y, Reynolds HY. State of the art. Macrophages and polymorphonuclear neutrophils in lung defense and injury. Am Rev Respir Dis 1990; 141: 471-501.

13 Donnelly SC, Haslett C. Cellular mechanisms of acute lung injury: implications for future treatment in the adult respiratory distress syndrome. Thorax 1992; 47 260-3.

14 Faden $\mathrm{H}$, Ogra P. Neutrophils and antiviral defense. Pediatr Infect Dis 1986; 5: 86-93.

15 Turner RB. The role of neutrophils in the pathogenesis of rhinovirus infections. Pediatr Infect Dis 1990; 9: 832-5.

16 Smith TF, McIntosh K, Fishaut M, Henson PM. Activation of complement by cells infected with respiratory syncytial virus. Infect Immun 1981; 33: 43-8.

17 Edwards KM, Snyder PA, Wright PF. Complement activation by respiratory syncytial virus infected cells. Arch

Virol 1986; 88: 49-56.
18 Kaul HW, Welliver RC, Faden HS. Respiratory syncytial virus specific immune complexes in nasopharyngeal secretions after natural infection with RSV. F Clin Lab Immuno 1984; 15: 187-90

19 Faden H, Kaul TN, Ogra PL. Activation of oxidative and arachidonic acid metabolism in neutrophils by respiratory syncytial virus antibody complexes: possible role in disease. $\mathcal{F}$ Infect Dis 1983; 148: 110-6. 
20 Chanock RM, Kapikian AZ, Mills J, Bethesda, Kim HW, Parrott RH. Influence of immunological factors in respiratory syncytial virus disease of the lower respiratory tract. Arch Environ Health 1970; 21: 347-55.

21 Becker S, Koren HS, Henke DC. Interleukin-8 expression in normal nasal epithelium and its modulation by infection with respiratory syncytial virus and cytokines tumour necrosis factor, interleukin-1 and interleukin-6. $\mathrm{Am} f$ Respir Cell Mol Biol 1993; 8: 20-7.

22 Becker S, Quay J, Soukup J. Cytokine (tumour necrosis factor, IL -6 and Il-8) production by respiratory syncytial virus-infected human alveolar macrophages. $¥$ Immunol 1991; 12: 4307-12.

23 Leonard EJ, Yoshimura T. Neutrophil attractant/activation protein-1 (NAP-1 [interleukin-8]). Am $\mathcal{F}$ Respir Cell Mol 479-86.

24 Carr R, Pumford D, Davies JM. Neutrophil chemotaxis and adhesion in preterm babies. Arch Dis Child 1992; 67: 813-7.

25 Dos Santos C, Davidson D. Neutrophil chemotaxis to leukotriene $\mathrm{B}_{4}$ in vitro is decreased for the human neonate. Pediatr Res 1993; 33: 242-6.

26 Neligan GA, Steiner H, Gardner PS, McQuillan J. Respiratory syncytial virus infection of the newborn. $B M^{f}$ 1970; iii: 413-8.

27 Kimpen JL, Garofalo R, Welliver RC, Ogra PL. Activation of human eosinophiles in-vitro by respiratory syncytial virus. Pediatr Res 1992; 32: 160-4.

28 Garofalo R, Kimpen JLL, Welliver RC, Ogra PL. Eosinophil degranulation in the respiratory tract during naturally acquired syncytial virus infection. $f$ Pediatr 1992; 120: 28-32.

29 Isaacs D, Bangham CRM, McMichael AJ. Cell-mediated cytotoxic response to respiratory syncytial virus in infants with bronchiolitis. Lancet 1987; ii: 769-71.

30 Openshaw PJM. Pulmonary epithelial T cells induced by viral infection express $\mathrm{T}$ cell receptors $\alpha \beta$. Eur f Immunol 1991; 21: 803-6.

31 Walters EH, Gardiner PV. Bronchoalveolar lavage as a research tool. Thorax 1991; 46: 613-8.

32 BAL co-operative group steering committee. Bronchoalveolar lavage constituents in healthy individuals, idiopathic pulmonary fibrosis and selected comparison idiopathic pulmonary fibrosis and selected comparison

33 Clement A, Chadelat K, Masliah J, et al. A controlled study of oxygen metabolite release by alveolar macrophages from children with interstitial lung disease. Am Rev Respir Dis 1987; 136: 1424-8.

34 Green M, Brayer AF, Schenkman KA, Wald ER. Duration of hospitalisation in previously well infants with respiratory syncytial virus infection. $\mathcal{F}$ Pediatr Infect Dis 1989; 8: 601-5.

35 Hall CB, Hall WJ, Speers DM. Clinical physiological manifestations of bronchiolitis and pneumonia. Am $\Im \mathrm{Dis} C h i l d$ 1979; 133: 798-802.

36 Hogg JC, Williams J, Richardson JB, MacKlem PT, Thurlbeck WM. Age as a factor in the distribution of lower airway conductance and in the pathologic anatomy of obstructive lung disease. $N$ Engl $\mathcal{f}$ Med 1970; 282: 1283-7. 